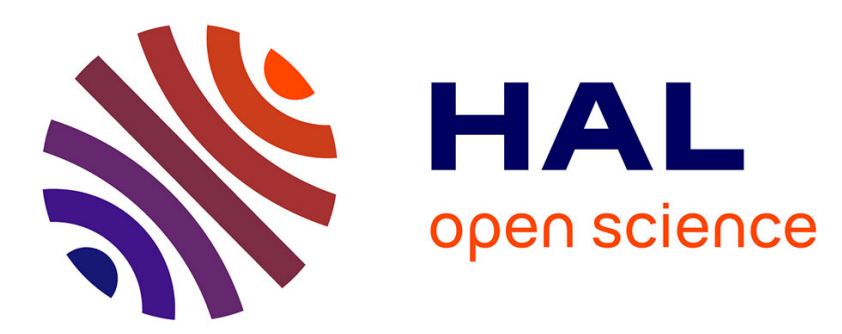

\title{
Knowledge-intensive Business Services: Processing Knowledge and Producing Innovation
}

\author{
Faïz Gallouj
}

\section{To cite this version:}

Faïz Gallouj. Knowledge-intensive Business Services: Processing Knowledge and Producing Innovation. Economics and socioeconomics of services International Conference, University Lille 1, Clersé, Jun 2000, Lille, Roubiax, France. 10.4337/9781781950203.00021 . halshs-01113809

\section{HAL Id: halshs-01113809 \\ https://shs.hal.science/halshs-01113809}

Submitted on 6 Feb 2015

HAL is a multi-disciplinary open access archive for the deposit and dissemination of scientific research documents, whether they are published or not. The documents may come from teaching and research institutions in France or abroad, or from public or private research centers.
L'archive ouverte pluridisciplinaire HAL, est destinée au dépôt et à la diffusion de documents scientifiques de niveau recherche, publiés ou non, émanant des établissements d'enseignement et de recherche français ou étrangers, des laboratoires publics ou privés. 


\title{
Economics and socioeconomics of services \\ International Conference, Lille-Roubaix, 22, 23 June 2000
}

\author{
Knowledge-intensive business services: processing knowledge and producing innovation \\ Faïz Gallouj \\ Clersé (Ifrési and Université de Lille 1)
}

\begin{abstract}
Knowledge-intensive business services (KIBS) can be defined as activities in which knowledge is both the input and the main output. The aim of this paper is twofold. Firstly, it seeks to describe a normal service transaction in terms of the various basic modes of knowledge processing and production used by KIBS firms. Secondly, it seeks to establish the links and boundaries between a normal transaction of this kind and innovation, whether produced within or through the use of KIBS.
\end{abstract}

\section{Introduction}

Services constitute a challenge to economic theory, both conceptually and methodologically. It is not always easy, indeed, to define the outputs of service activities. They are often indissociable from the process by which they are produced and have to be considered within different time frames: that in which the service itself is produced and that in which the effect of the service makes itself felt. As a result, it is difficult to define innovation, evaluate performance and analyse markets ${ }^{1}$.

In knowledge-intensive business services (KIBS), that is research, consultancy and engineering business services, these difficulties are compounded by those associated with another problematic area of economic theory, namely that of knowledge. Knowledge is also a concept that has multiple meanings, and one that poses important theoretical and methodological problems. Nor is it always clear where the boundary lies between knowledge and other notions such as data, information, competences, capabilities and so on.

One of the fundamental characteristics of what is called "the knowledge-based economy" is the spectacular growth in economic transactions relating to knowledge itself (Maskell and Malmberg, 1999, Antonelli, 1999). KIBS firms are organisations that are particularly representative of this "economy", since knowledge constitutes both their main input and output. These firms are both processors and producers of knowledge. The aim of this paper is to examine the modes of knowledge processing and production used in such firms and their implications for the question of innovation produced in and through the use of KIBS. These two aspects of innovation in KIBS are not independent of each other: the first denotes the processes of innovation within KIBS firms, while the second relates to the contribution of KIBS providers to innovation in their client organisations.

This paper is divided into three parts. The first is given over to a summary of the economic debate on the nature of knowledge and on the distinction between information, knowledge and competences. In section 2 , we examine the basic mechanisms of knowledge processing and production, firstly within the general

\footnotetext{
${ }^{1}$ For a recent assessment of these various issues cf. in particular C. and F. Gallouj (1996), Sundbo (1998), Gadrey (1996), De Bandt and Gadrey (1994) and Rubacalba-Bermejo (1999).
} 
framework of learning cycles or spirals (Noteboom, 1999; Nonaka, 1994; Nonaka and Takeuchi, 1995) and then more specifically in the context of KIBS transactions. In section 3, we seek to mark out the boundary and establish the nature of the links between these modes of knowledge processing and innovation in and through the use of KIBS.

\section{Differing conceptions of information and knowledge}

Knowledge, like services, continues to be a vague concept, despite the efforts of economic theorists to clarify matters. The boundaries between the notions of 1) data, 2) information, 3) knowledge, 4) competences and 5) capabilities are not always clearly delineated. Nevertheless, there is widespread agreement on at least two points.

1) The semantic content (that is the extent to which context is taken into account) is generally considered to increase in the course of a move from category 1 to category 3 . Thus a given category cannot be reduced to the mere summation of elements from the preceding category. For example, knowledge cannot be reduced to the sum of a sequence of discrete items of information, since different individuals can extract different knowledge from the same information and any one individual can, in different circumstances, extract new knowledge from that same information. Within a bounded rationality framework, the phenomena of "interpretative ambiguity" (Fransman, 1994) and "causal ambiguity" (Lippman and Rumelt, 1982) can be called on to interpret these distortions.

2) The notions of competence and capability (often regarded as synonyms) open up a breach in the sequence of increasing semantic content, since they reflect an "aptitude for performing (successfully) ${ }^{2}$ with confidence..." (Nelson, 1994) that is based on data, information and knowledge. In other words, competences do indeed have a cognitive element but they also reflect other aptitudes such as manual dexterity and sensory capacities (Senker, 1995).

All these analytical categories apply to the service providers that are the object of analysis in this paper. Indeed, they can be defined as organisations that mobilise a certain number of competences in order to process data, information and knowledge that can be used to produce the data, information and knowledge that crystallise in various ways in what is termed a solution (to a problem).

Starting from the hypothesis that what ultimately concerns the client firm is the (direct or indirect ${ }^{3}$ ) acquisition of meaning in the hope of shedding light on changing internal and external environments ${ }^{4}$, we can say that it is knowledge (the category with the greatest semantic content) that lies at the heart of the activities of KIBS providers. The service provider's competence can be defined as an aptitude for processing that knowledge in different ways. The various forms this competence takes, with which this paper is chiefly concerned and which are examined in section 2, are closely linked to the particular characteristics of knowledge as a commodity. These characteristics can be considered from three different points of view: the object of the knowledge, its nature and its economic properties.

\subsection{The object of knowledge}

\footnotetext{
${ }^{2}$ In the case of the "aptitude for performing (successfully) better than others", the term "core competences" is used (Teece, 1998).

${ }^{3}$ When the service provider supplies raw materials that have to be processed by the client in order to produce meaning.

${ }^{4}$ It is in fact the dynamic of the particular environment that justifies the use of service providers, and it is in the most dynamic environments, that is the most rapidly changing areas of expertise, that the use of KIS is growing most quickly (Wolff and Baumol, 1987, cited in Starbuck, 1996).
} 
The object of knowledge may be an understanding of the physical and natural world or of the economic and social world. Thus this first point of view denotes the distinction between 1) scientific and technical knowledge (in the strict sense of the term), which describes the laws governing the functioning of the physical and natural world and which is the product of research, and 2) economic and social knowledge which, from the perspective of firms and organisations, relates to the states of the internal and external economic and social environments (including the technological environments). In reality, there is no reason why the first category (scientific and technical knowledge) should not also include knowledge relating to the principles governing the economic and social world when they too are the result of research activity (in economics, law, sociology or psychology).

Paradoxically, and with few exceptions (notably Hayek, 1945), economic theories of information and knowledge, whether in traditional economics (Arrow, 1962) or in the new economics of science (Dasgupta and David, 1994), focus essentially on the first category (in its strict sense). Thus Machlup (1984) himself identifies three types of knowledge: 1) technological knowledge, 2) useful nontechnological knowledge and 3) and "dispersed" knowledge, that is information on unique and ephemeral events in economic life. However, as Ribault (1991) notes, he concerns himself essentially only with the first category, namely with scientific and technical knowledge.

The provision of KIBS can encompass the whole range of functions that constitute a firm's activity. Consequently, a KIBS provider may be required to assume responsibility for the dynamic of different environments: economic, legal, social, scientific and technological, etc. Thus in any analysis of the activity of KIBS firms, account has to be taken of all existing types of knowledge and not simply of scientific and technical knowledge.

\subsection{The nature of knowledge}

The question of the nature of knowledge can be examined at various levels. Firstly, it should be noted that, like the notion of service itself, the term knowledge denotes both a process and an outcome. The various forms of knowledge also differ in the extent of their sphere of application. Thus there are general and specific forms of knowledge. Another distinction is made between declarative, procedural and causal knowledge in order to denote, respectively, the content, modalities and explanations of a given event (Cohen and Bacdayan, 1996). These three categories constitute a subset of the typology developed by Lundvall and Johnson (1994), in which four forms of knowledge are identified: know-what, know-how, know-why and know-who.

However, the most widely used distinction is the one frequently associated with Polanyi (1983), which contrasts tacit knowledge (sometimes known as implicit or embodied knowledge) with codified knowledge. Tacit knowledge is subjective and difficult to articulate and codify, that is to express in the form of language or written symbols. For Polanyi, it reflects the fact that individuals know more than they are capable of expressing. In reality, the tacit nature of knowledge can be considered not only at the level of the individual but also at that of the group or organisation. More generally, it can be said that knowledge can be embodied in various media: individuals, organisations (in the form of procedures or routines) or technical systems. Conversely, codified knowledge can readily be expressed in the form of signs and verbal or written symbols.

As we shall see, the importance of this distinction lies in the differences between the various regimes of appropriation and in the ease with which knowledge can be transferred. Codified knowledge is easy to transfer and difficult to appropriate. Tacit knowledge can be transferred, but the process is slower and considerably more costly and the regime of appropriation higher. As Winter (1987) stresses, the ease

with which knowledge can be transferred increases in line with other criteria: the opportunity to observe 
the knowledge in use, its simplicity and its relative autonomy (as opposed to its integration into a system). Moreover, the extent to which knowledge is codified may not be an accurate indicator of the ease with which it can be transferred. Indeed, the degree of codification may well be a reflection not of any intrinsic technical characteristic of the knowledge but rather of a transitory state that is likely to change in accordance with technical, intellectual or social conditions. Thus in order accurately to assess the ease of transfer, we have to focus on the following three continuums: tacit-articulable, teachable-not teachable and inarticulated-articulated, since even tacit knowledge can be more or less teachable (and therefore transferable) and articulable knowledge may or may not be articulated depending on the strategy or circumstances.

\subsection{The economic properties of knowledge}

In the traditional economic literature, there is a general belief, derived in particular from the works of Arrow (1962), that knowledge (regarded as comparable to technological information) has two properties that distinguish it from traditional tangible goods but make it similar to public goods ${ }^{5}$.

1) Knowledge is a good whose exclusivity is difficult to maintain: it is a "non-excludable" good. Despite firms' efforts to contain it, knowledge has a propensity to escape into the external environment, there to disperse itself through a variety of channels to the benefit (at no extra cost) of other economic agents. Thus the processing and production of knowledge give rise to positive externalities (spillover) that are difficult to control.

2) Knowledge is a good that is not exhausted in use. Each individual can consume knowledge without reducing others' consumption of it, however numerous those others may be. In order to consume such knowledge, economic agents do not enter into rivalry or competition with each other. Thus it is a nonrival good. The marginal cost of its consumption by an (additional) consumer is close to zero.

Taken in conjunction with each other, these two characteristics of the use of knowledge (nonexcludability and non-rivalry) have certain economic consequences:

- knowledge cannot be appropriated by its producer (or only at excessively high cost);

- it can be transferred easily and at low cost between individuals and across time and space;

- the sale of knowledge poses a difficult problem, since no such sale can take place without disclosure but disclosure renders the sale null and void.

This concept of knowledge is not without value for those seeking to understand knowledge-intensive business services. Some of the transactions involved do indeed relate to information that was either codified initially or became codified as a result of the service provider's intervention. However, this concept does not adequately describe the full diversity of forms taken by KIBS transactions.

The recently developed neo-Schumpeterian approach marks a break with this concept of knowledge as information and as a public good. It alters the economic characteristics of knowledge by attributing a significant role to tacit knowledge and to the nature of the relationships between tacit and codified knowledge and by emphasising the cumulative and specific nature of knowledge. Tacit (or embodied) knowledge is considered, on the one hand, as a rival good and, on the other hand, as an excludable good, that is one that is easily appropriated. In other words, such knowledge is a genuine private good. Whether tacit or codified, knowledge depends on context and introduces irreversibilities into learning processes. Thus knowledge can be stored, accumulated and capitalised, and the competitive advantage of

\footnotetext{
${ }^{5}$ For a review and more detailed discussion of these questions cf. in particular (to cite just a few recent studies) Dasgupta and David (1994), Cowan and Foray (1998), Callon (1999), Antonelli (1999) and Foray and Mairesse (1999).
} 
external KIBS providers over internal specialists can be said to lie less in the reduction of transaction costs than in quantitative and qualitative differences and complementarities relating to knowledge, what Noteboom (1992) calls external economies of cognitive scope.

\section{Different basic mechanisms for producing and processing knowledge}

Since the activity of KIBS providers can be said to consist of the production of knowledge from knowledge, their competences can be said to reside in their aptitude for processing and producing knowledge on behalf of a client. Thus any attempt to investigate the competences of KIBS providers must seek to clarify the content of the general terms processing and producing. Although they are not directly concerned with KIBS, the economics and organisation science literatures contain some interesting studies of basic knowledge-processing mechanisms that might shed some light on our analysis of the competences of KIBS providers. However, the competences mobilised within a KIBS relationship cannot be considered independently of the mechanisms located within the "black box" of knowledgeintensive business services (and particularly those related to the accumulation of knowledge).

\subsection{The basic knowledge-processing mechanisms}

Although the literature contains many studies of knowledge processing, there have been few attempts to focus in a precise and articulated way on the basic procedures by which knowledge is processed. We outline below two of the exceptions to this general rule (Noteboom, 1999; Nonaka, 1994; see also Nonaka and Takeuchi, 1995).

a) Noteboom (1999) sets out to investigate the way in which firms attempt to reconcile continuity and change or, in other words, incremental and radical innovation or even uncertainty and risk. The problem here is one of abduction ${ }^{6}$, in the sense of the term defined by Peirce (1957) as he sought to understand the mechanisms that facilitate the transition from one practice to another. Drawing his inspiration from the works of Piaget (1970) on individual cognition, Noteboom (1999) describes five (heuristic) principles of abduction which, taken in succession, constitute a learning cycle.

- Generalisation. This first principle of abduction describes the application of a tried and tested practice to new but adjoining contexts. While it satisfies the demands of current production, this principle also reveals the limits of generalisation and triggers the following principle.

- Differentiation. This denotes the adaptation to the local context of practices whose limits have been revealed by generalisation. Differentiation represents an attempt to circumvent these limits. Once again, it allows current production to continue while at the same time introducing new adaptations in accordance with another principle of abduction, namely reciprocation.

- Reciprocation. This is the principle whereby, in any given context, different but parallel practices are compared with a view to exchanging the most effective elements in those practices. Thus metaphor and analogy are principles of reciprocation.

- Accommodation (or combination). Repeated implementation of the principles of differentiation and reciprocation may weaken the practice in question and impact adversely on its efficiency and effectiveness. The opportunities for standardisation and realising economies of scale gradually decline and the practice becomes more complex, losing its coherence as it is adapted and augmented. Once a certain stage has been reached, a more fundamental restructuring becomes necessary. This restructuring consists of establishing a new practice by combining elements derived from different practices. This principle of accommodation or combination leads to the creation of novelty in an indeterminate form.

\footnotetext{
${ }^{6}$ Etymologically: "lead or take away..."
} 
- Consolidation. This principle involved the transformation of an indeterminate novelty into a "dominant design", in the sense of the term used by Abernathy and Utterback (1978). Once this dominant design has been established, a new learning cycle (initiated by the generalisation principle) can get under way.

The learning cycle outlined above gives rise to several comments.

- It applies not only to individuals but also to organisations, industries and even countries.

- It has to be considered as an heuristic procedure and not as a logical sequence. Some principles may be superimposed on each other, others may be absent, etc.

- It links the principles of continuity, exploitation and equilibrium, or first-order learning (consolidation and generalisation), with those of exploration and disequilibrium, or second-order learning (differentiation, reciprocation and accommodation).

b) The studies by Nonaka (1994) and Nonaka and Takeuchi (1995) also offer a potentially very fruitful perspective on the modes of knowledge processing. Although they too are interested in the emergence of innovation, these authors put the emphasis not on the diversity of the principles of abduction but rather on the variety of "social interactions between tacit and explicit knowledge". These social interactions, which constitute different modes of knowledge conversion or transfer, fall into one of four categories.

- Socialisation. This mode of conversion denotes social interactions in which tacit knowledge is exchanged. Socialisation is based on and contributes to the construction of a knowledge base that is shared by the group or organisation in question. It is closely linked to the notion of experience, in the sense that tacit knowledge is acquired through experience.

- Externalisation. This denotes the conversion of tacit knowledge into codified knowledge. This form of knowledge processing, which goes hand in hand with a certain loss of meaning, may take the form of metaphors, analogies, concepts, hypotheses or models.

- Combination. This is a mode of knowledge conversion in which explicit knowledge is combined with more explicit knowledge and fed into the common base of explicit knowledge. The process of combination is facilitated by the use of various media: written documents, communications networks, etc. - Internalisation. This denotes the transformation of explicit knowledge into tacit knowledge. Internalisation is often synonymous with learning by doing (imitation, experience).

These four modes of knowledge conversion (socialisation, externalisation, combination and internalisation) are not independent of each other. Sequenced as above, they constitute a learning spiral.

The studies outlined here deal with the question of knowledge processing from two different but complementary angles. The first puts the emphasis primarily on the principles of abduction. A distinction is made between exploration and exploitation mechanisms (in the sense attributed to the terms by March [1991]), depending on how far the mode of knowledge processing in question leads the individual or organisation away from the initial cognitive state. The second stresses the epistemological dimension of knowledge, that is its tacit or explicit nature.

These studies express the view that the learning cycle or spiral can be considered at various levels of analysis (the individual, the group, the organisation, etc.) or that analysis of it has to be conducted at several different levels. We are concerned here with one particular situation, namely service transactions involving a client and a KIBS provider. Our purpose, therefore, is to examine the modes of knowledge processing deployed in this particular situation.

\subsection{The competences of KIBS providers}

Drawing on the definition of services proposed by Gadrey (2000), we can say that the activity of KIBS providers consists of placing at the disposition of clients capabilities for processing information and 
knowledge. These capabilities are what we call the competences of KIBS providers. Our aim here is to highlight the various forms that these competences take. In so doing, we will draw on the studies examined above while at the same time seeking to remain close to the actual forms of knowledge processing deployed by KIBS providers.

A KIBS transaction can be said to bring three elements into play (Figure 1):

1) the source (S) of the input knowledge;

2) the receiver $(\mathrm{R})$ of the output knowledge;

$3)$ the processor $(\mathrm{P})$ of the input knowledge and the (co) producer of the output knowledge.

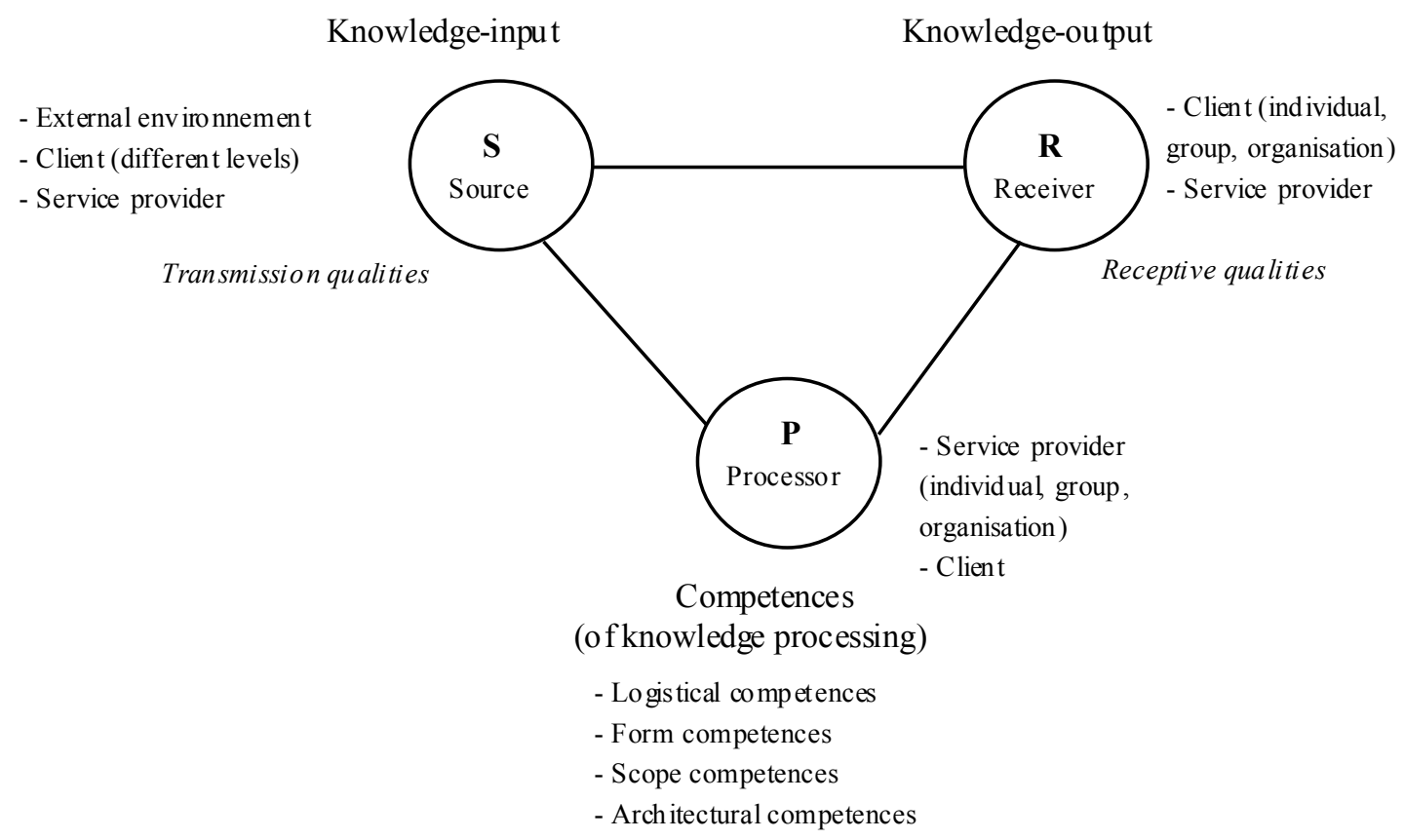

Figure 1: The KIBS transaction as a form of knowledge processing

This representation is an extremely simplistic one. It covers a number of more complex configurations.

Thus the receiver of the knowledge $(\mathrm{R})$ may denote the individual client, a group within the organisation or the client organisation as a whole. The service provider itself is also a receiver, to the extent that it seeks to store the knowledge that emerges from each new transaction in its organisational memory in order to use it later as input knowledge (cf. § 2.3).

The source of the knowledge (S) is also a heterogeneous category encompassing a) the client itself (i.e. the receiver in the various senses of the term), b) the client's external environment and c) the processor, considered as a database of knowledge accumulated in the course of repeated KIBS transactions. While it is possible that just one of these components may be brought into play in a KIBS transaction, it is more usual for them all to be mobilised.

The processor $(\mathrm{P})$ is the service provider, which may also be regarded as an individual, a project group or an organisation. The client itself is a knowledge processor, particularly when the service is co-produced and not simply subcontracted.

Some of the components of a KIBS transaction (S, R, P) may merge with each other. In this case, they indicate the existence of reflexive relationships: for example, an individual or a group may be both the 
source and the receiver of knowledge. Usually, however, their very heterogeneity means that these various components bring different subunits into contact with each other. For example, it is commonly the case in large firms that the source of knowledge is different from the receiver. In particular, as Cohendet et al. (1999) stress, the problem facing large international firms today is how to ensure that (localised) knowledge circulates internally between different sites.

The main activity of the service provider as a processor of knowledge is to transfer, as effectively and efficiently as possible, the knowledge crystallised in a solution from a source to a receiver. The term transfer denotes both a physical movement and the economic circulation of a good (with all the difficulties of transferring ownership inherent in this particular commodity). The forms taken by this transfer equate to the interventions of the KIBS provider in the various aspects of the knowledge in question (Table 1): its (physical) circulation, its form, its scope and its structure. However, the quality of the various basic transfer mechanisms also depends on certain characteristics of the source and the receiver.

\section{a) The characteristics of the source and the receiver}

The qualities of the receiver can be described, in very simple terms, as receptive qualities. They denote the cognitive aptitudes, the "technical" conditions and the attitudes (behaviour patterns, strategies) that encourage the acquisition of knowledge. They reflect the additive and complementary nature of knowledge. The quality of a KIBS provider's intervention depends on the receptive qualities of the receiver. These qualities permit or facilitate communication and reduce informational asymmetries in the provision of the service. Thus these receptive qualities are weakened when a client organisation does not have an internal department made up of experts in a given function (for example, a legal department in the case of the provision of a legal service). These receptive qualities may also be affected by internal disputes and by unfavourable individual or group behaviour (a refusal to learn), particularly when the receiver feels threatened by the new knowledge.

This question occupies a position of some importance in the economic and socio-economic literature, where it is known by various names. In economic analyses that draw their inspiration from the phenomena of percolation in the physical sciences, it is denoted by the term receptivity (Antonelli, 1996). In sociology (and particularly in the sociology of science), the term translation capabilities is used (Callon, 1986), while in the economics of technical change (Cohen and Levinthal, 1990), the term absorptive capacities is used. These absorptive capacities relate essentially to scientific and technical knowledge. Thus the receptive qualities that are the object of our analysis here can be interpreted as extended receptivity or extended absorptive capacity, since they relate to all the forms of knowledge that might be subject to processing by a KIBS provider (cf. $\S 1.1$ ). These receptive qualities are to some extent given, but they can also be improved by the interventions of the KIBS provider.

The source of the knowledge may also have a certain number of characteristics that facilitate the flow of knowledge to a greater or lesser extent. As opposed to the receptive qualities discussed above, the propensity of a source to deliver up its knowledge will be denoted by the term transmission qualities. These transmission qualities also denote the cognitive aptitudes, the technical conditions and the attitudes of a source, which may be more or less favourable to the transfer or, conversely, retention of knowledge. Thus these transmission capacities are dependent on the nature of knowledge in question, on the cognitive characteristics (aptitudes) of the various elements that make up the source and on the attitudes of those elements to the sharing of knowledge. The transmission qualities of the source are generally increased when the knowledge is codified. They decline when this knowledge is regarded as strategic by the source (or its various components) or when the purpose to which the knowledge is put is likely, in one way or another, to call into question the source itself. Mistrust of this kind is not uncommon in audit services 
and, more generally, in knowledge-intensive business services of a therapeutic nature, that is those seeking to provide answers to what Kubr (1988) calls corrective problems.

These transmission capacities are also partly given, but the service provider's intervention may help to improve them. Since a source must exist before transmission can take place, the first form that such an intervention can take is to locate the source of the knowledge, what Gibbons and Johnston (1974) call "knowledge about knowledge". In fact, outside of the ideal-typical situation of the standard classical market, locating the source of the knowledge is not such an easy task. For this reason, the typology of knowledge drawn up by Lundvall and Johnson (1994), namely the know-what, know-why, know-how and know-who, needs to be supplemented by a fifth type of knowledge that we will denote by the term knowwhere. This additional type signifies the ability to identify and locate the place where the knowledge is to be found (that is the source).

\section{b) Competences relating to the circulation of knowledge (logistical competences)}

The circulation of knowledge may take a very simple basic form that we describe as the linear transfer of knowledge or basic logistical competence. Here, knowledge is reduced to the status of information. The service provider is regarded as a mere processor of information, a simple intermediary whose activity is limited to moving the information ("physically") from the source where it is located to the receiver who purchases it or who is designated by the purchaser. In this case, the knowledge is not modified as it moves from $\mathrm{S}$ to $\mathrm{R}$ : the input knowledge is identical to the output knowledge. Some market research services, the use of on-line databases and some aspects of recruitment consultancy or of the transfer of technical systems by IT consultants can be described in these terms.

This basic logistical competence is regarded here as an autonomous service. Usually, however, the transfer or circulation of knowledge includes some form of knowledge processing, or in other words more complex competences. In most cases, indeed, this basic logistical competence is combined with other competences that reflect an aptitude for modifying the nature of the knowledge and its economic properties.

The links between the basic logistical competence and the other competences are complex. They may be implemented before the knowledge is circulated, or they may succeed it, accompany it or merge into one with it. If the categories outlined above are examined alongside a number of empirical studies (Gallouj, 1991 ; Gadrey et al. 1992 ; Bessant and Rush, 1995 ; Miles et al., 1995 ; Bilderbeek and Den Hertog, 1997), it is evident that the activity of KIBS providers involved in a service relationship can be described relatively satisfactorily in terms of six basic competences. Although they are difficult to dissociate from each other within the framework of any given service, these competences can be separated out analytically. They can be broken down into three groups, each containing two opposing principles, which describe the changes of state the knowledge undergoes as it flows between the source and the receiver.

\section{c) Competences relating to the form of knowledge (competences of form, or "shaping" competences)}

The first pair of competences describes the capacity to alter the form (codified or tacit) taken by the knowledge in question. It is largely coterminous with, though somewhat more extensive than, the conversion mechanisms that Nonaka (1994) denotes by the terms externalisation and internalisation.

- Externalisation is undoubtedly the most studied mode of knowledge processing, particularly because it is associated with the increasing importance of information technologies. Externalisation is synonymous with formalisation, with codification (that is the "conversion of knowledge into a message that can then be manipulated as information", Cowan and Foray, 1988) or even with "forms investments" (that is the "costly establishment of a relationship that remains stable over a certain period of time", Thévenot, 1988). 
In the context of a KIBS relationship, and to use terms coined by Nonaka (1994), externalisation denotes the transformation of knowledge that is tacit at the source into knowledge that is codified at the receiver. This transformation of the knowledge makes it easier to manipulate and gives it a certain stability.

Nonaka's definition can be extended to include a particular case already alluded to above, namely a situation that arises frequently in large firms whereby (useful) knowledge that exists within an organisation is not recognised as such by the organisation, irrespective of its form (tacit or codified). It is, as it were, involuntarily concealed (or tacit) because it lies outside the firm's capacity for introspection. As Kirzner (1979, quoted in Maskell and Malmberg, 1999) observes, this type of knowledge highlights weaknesses in the standard theories of individual decision-making:

"Ignorance of knowledge that might be spontaneously, undeliberately absorbed can...never be explained in terms of anything other than itself. Such ignorance is simply there. It cannot be accounted for on the grounds of high search and learning costs, since no searching or learning is needed at all even, to repeat, at zero cost... Ignorance of knowledge that can be absorbed without decision is simply the expression and the evidence of a sheer failure to notice what is there to be seen. It can be given a name - lack of entrepreneurial alertness - but it cannot be explained in terms of the standard economics of micro-theory, the theory of deliberate individual decisions" (Kirzner, 1979, p. 145).

By deploying this particular externalisation competence, and thereby making firms actively aware of knowledge they have hitherto ignored and helping them to rediscover and create it socially, KIBS providers are helping to stimulate what Kirzner (1979) calls "entrepreneurial alertness".

More generally, the aim of externalisation is to facilitate the transfer of knowledge by reducing transaction costs (Zander and Kogut, at 1995). Thus externalisation facilitates the implementation of basic logistical competences. It facilitates the absorption of knowledge by the client (learning) and increases the service provider's pedagogical efficiency (teaching).

However, externalisation poses problems of appropriation for the service provider. It makes imitation easier. It is unlikely that a service provider will be able to sell the same knowledge twice to the same client, and it may be very easy for the client to duplicate that knowledge and diffuse it internally. However, as Senker (1995) and Callon (1999) in particular stress, some of the codified knowledge thus created is learned and applied tacitly. Moreover, the process of externalisation itself is based on tacit knowledge that exists within the service- providing organisation. Externalisation cannot be taken for granted: it always depends on the extent to which the knowledge can be codified, which varies from case to case.

- Internalisation denotes the transformation of knowledge that is codified at the source into knowledge that is tacit at the receiver. In this case, the service provider supports the client during the learning process (pedagogical function). Internalisation requires the service provider to become involved voluntarily and actively in the client's imitation process. Internalisation cannot be achieved without close interaction between the client and service provider. It enables the client to appropriate the knowledge more easily. Here, the logistical competence and the internalisation process become one and the same thing. Internalisation may have another advantage over externalisation. The cost of codification may be too high, particularly when the practices described by the knowledge are recursive in nature. Internalisation eliminates the need to explain and codify ad infinitum.

Internalisation transforms a public good into a private good with a high rate of appropriation. However, the knowledge transferred by means of this internalisation competence can be used effectively only by the front-office staff in the client firm, since it is difficult to diffuse it rapidly throughout the organisation as a whole. 


\section{d) Competences relating to the scope of knowledge (competences of scope)}

The second pair of competences reflects the evolution of the scope of knowledge. It contrasts competences relating to generalisation with those relating to localisation, which cover the same ground as but are not to be confused with the principles of generalisation and specification developed by Noteboom (1989). Evolutionary theory, in particular, has attributed a key role to localised technological knowledge (Antonelli, 1996, 1999).

- Generalisation denotes the process whereby knowledge (tacit or codified) that is specific at the source is transformed into knowledge (tacit or codified) that is general when it reaches the receiver. This competence extends the range of application of a particular item of knowledge, or its audience (the scope of the "knowledge about knowledge", as it were). Nonaka's notion of socialisation could be regarded as a particular case of generalisation, to the extent that it is an instrument for the generalisation of tacit knowledge. This socialisation requires a degree of interaction that is at least as high, if not higher, than that required for internalisation. In implementing the generalisation principle, KIBS providers are helping to reduce "cognitive distance" (Noteboom, 1999) both inside and outside the receiving organisation (the cognitive distance between and within firms if the organisation is a firm). Thus it encourages what might be called "cognitive alignment", which facilitates the exchange of knowledge.

- Localisation (or differentiation or specification) is the transformation of knowledge that is general at the source into knowledge adapted to the local context of the receiving organisation. Again, this knowledge may be both tacit and codified. Localisation increases the extent to which the knowledge can be appropriated by the client. Of course, this appropriation is made all the easier by the tacit knowledge put in place by the localisation process. In this case, the solution proposed or co-produced by the service provider is an exclusive one shared by the client and the service provider. It is not widely diffused beyond the group. Nevertheless, it should be noted that localisation makes such diffusion not only difficult and costly (particularly in the case of tacit knowledge) but sometimes also useless (because of the local nature of knowledge). In contrast to generalisation, localisation can be said to introduce "cognitive distance" between the receiver and the external environment, which may reduce the diffusion of knowledge beyond the local level. If the receiving organisation is a firm, localisation increases the cognitive distance between firms but sharply reduces that within firms.

\section{e) Competences relating to the structure or morphology of knowledge (architectural or combinatory competences)}

In the course of a transaction, a KIBS provider may modify not only the form and scope of the knowledge in question but also its architecture. In order to highlight the two contrasting modes of the architectural or combinatory competence, we will replace the combination principle adopted by Nonaka (1994) and the accommodation principle developed by Noteboom (1999) with the association and dissociation principles.

- Association involves supplying to the receiver, in combined form, items or sets of knowledge (of different forms) that were originally discrete. Although this is a fundamental principle of the production of innovation in the Schumpeterian model, association is being considered here in a more general and mechanical way as one of the basic knowledge-processing mechanisms, which does not necessarily produce innovation.

Association concerns not only codified knowledge (as in Nonaka's framework) but also tacit knowledge (the socialisation mechanism comes into play once again here), as well as knowledge embodied in organisations, technical systems or individuals. Thus a range of different activities can be described by 
means of this basic mechanism: not only R\&D, which involves the production of new knowledge (tacit or codified) from various combinations of old knowledge (tacit or codified), but also associations between different organisations (collaborations, alliances), etc.

Like internalisation, the tacit exchange of knowledge or the association of tacit knowledge (socialisation) is a way of reducing the cost of codifying recursive knowledge.

- Dissociation, conversely, involves separating out a set of knowledge (of whatever form) in order to produce a different set of knowledge to be supplied to the client. As with association, the knowledge may be embodied in individuals, in technical systems or in organisations, and the process of dissociation may relate to the knowledge itself or to the media that carry it.

\begin{tabular}{|c|c|c|}
\hline $\begin{array}{l}\text { KIBS provider's intervention } \\
\text { in the various dimensions of } \\
\text { knowledge }\end{array}$ & Competence & Definition \\
\hline $\begin{array}{l}\text { Circulation } \\
\text { (logistical competences) }\end{array}$ & Basic logistical & $\begin{array}{l}\text { Mechanical transfer of knowledge functioning as } \\
\text { information }\end{array}$ \\
\hline \multirow[t]{2}{*}{$\begin{array}{l}\text { Intrinsic nature } \\
\text { (competences of form, or } \\
\text { "shaping" competences) }\end{array}$} & \begin{tabular}{|l} 
Externalisation \\
\end{tabular} & $\begin{array}{l}\text { Competence involving the transformation of } \\
\text { knowledge that is tacit at } \mathrm{S} \text { into knowledge that is } \\
\text { codified at } \mathrm{R}\end{array}$ \\
\hline & Internalisation & $\begin{array}{l}\text { Competence involving the transformation of } \\
\text { knowledge that is codified at } \mathrm{S} \text { into knowledge that is } \\
\text { tacit at } \mathrm{R}\end{array}$ \\
\hline \multirow[t]{2}{*}{$\begin{array}{l}\text { Reach or scope (competences } \\
\text { of scope) }\end{array}$} & Generalisation & $\begin{array}{l}\text { Competences involving an increase in the degree of } \\
\text { generality at R of knowledge that is local at } \mathrm{S}\end{array}$ \\
\hline & Localisation & $\begin{array}{l}\text { Competences involving an increase in the degree of } \\
\text { localisation at } \mathrm{R} \text { of knowledge that is general at } \mathrm{S}\end{array}$ \\
\hline \multirow[t]{2}{*}{$\begin{array}{l}\text { Structure or } \\
\text { (architectural or } \\
\text { competences) }\end{array}$} & Association & $\begin{array}{l}\text { Competences involving the association of knowledge } \\
\text { existing at } \mathrm{S} \text { in order to produce different knowledge } \\
\text { at } \mathrm{R}\end{array}$ \\
\hline & Dissociation & $\begin{array}{l}\text { Competences involving the dissociation of knowledge } \\
\text { existing at } \mathrm{S} \text { in order to produce different knowledge } \\
\text { at } \mathrm{R}\end{array}$ \\
\hline
\end{tabular}

Table 1: The competences of KIBS providers (modes of knowledge processing)

The seven basic knowledge processing mechanisms outlined above represent the various aspects of a multi-faceted interactive process, namely learning.

Here, this complex process involves the client and the KIBS provider. It has to be understood positively (learning in the strict sense), negatively (forgetting or unlearning) and neutrally (remembering), in other words as a mechanism for accumulating knowledge, for destroying obsolete knowledge (unlearning) and preserving a stock of knowledge (maintaining it at a given level). Thus it may be part of a KIBS provider's remit to destroy knowledge. Or, to put it another way, if learning is a cumulative process, then that cumulativeness is selective, since learning is a social phenomenon which, from the client firm's point of view, does not preclude creative forgetting (a means of dealing with the obsolescence of knowledge), or just plain forgetting (Johnson, 1992). These two types of forgetting may prompt service providers to help the client either to "forget" or, in the second case, to relearn or to remember. 
This learning process must also be perceived from the perspective of the "beneficiary" (service provider, client) and of the object of the process (knowledge and the modes of knowledge acquisition). From the point of view of the service provider, learning (or unlearning) may take a number of different forms:

- learning,

- teaching, that is imparting knowledge to clients through a variety of mechanisms, whether formalised (training) or not (learning by interacting),

- learning to learn (that is improving one's own absorptive capacity),

- teaching others to learn (that is improving their absorptive capacity).

These basic mechanisms, which describe some of the facets of the learning process, give rise to the following observations.

1) This typology of basic competences reconciles the typologies drawn up by Noteboom and Nonaka. It introduces a logistical competence that does not exist in these authors' typologies but which, on examination of the services actually supplied by KIBS providers, constitutes an important borderline case. It introduces the converse mechanism of association, which does not exist either in these two authors' typologies but which constitutes a not-insignificant mechanism for processing knowledge (and producing innovation) in KIBS, as well as in services in general. Generalisation, association and dissociation are defined in such a way that they can be applied to both tacit and codified knowledge. Thus socialisation does not disappear from our analysis but is incorporated into different principles.

2) The logistical competence comes always into play in the provision of KIBS, since what is involved is the transfer of knowledge from a source to a receiver. However, it is frequently incorporated into other mechanisms. This logistical competence (viewed independently) may also be regarded positively or negatively, since the transfer of knowledge may also be positive or negative (e.g. redundancy, discarding of a software package).

3) Although the seven basic competences outlined above can be distinguished from each other in analytical terms, they are actually implemented in more or less complex configurations. Each of these competences can be mobilised independently. The competence in question then becomes one and the same thing as the service transaction. Thus the provision of a given KIBS may consist of the mere circulation of knowledge: certain market research or auditing services have already been mentioned above by way of example. It may also involve the adaptation of a generic solution to a local situation, and vice versa, etc. More usually, however, a range of different basic competences is mobilised during the provision of a KIBS. In such situations, these various basic competences may be related to each other in various ways. For example, they may be deployed simultaneously or successively. Thus the association, generalisation or logistical principles are frequently proceeded by implementation of the externalisation principle, during which the knowledge in question is codified. Localisation often goes hand in hand with internalisation, which explains why these two mechanisms are frequently confused in the literature.

\subsection{The KIBS firm as a knowledge-accumulation system}

In the previous section, our analysis focused on the processing of knowledge within the framework of a given service relationship, that is at the interface between source and receiver. This processing affects the (physical) circulation, form, scope and morphology of the knowledge in question. Another aspect of knowledge must be taken into account, namely its cumulative nature (cf. $\S 1.3$ ). This aspect plays an extremely important role within KIBS firms, independently of any given service transaction.

Indeed, since the use of KIBS can be explained less by transaction costs than by cognitive differentials, the main objective of KIBS providers is to accumulate, capitalise and protect the knowledge derived from different service transactions, in other words to establish and maintain an organisational memory. 
This organisational memory is important for several reasons. It constitutes one of the sources of knowledge that can be drawn on for input in any given service relationship (cf. Figure 1). It can also be drawn on in situations in which the KIBS provider is helping a client with an innovation process. Finally, it constitutes an essential source of cognitive raw material for innovation within KIBS firms themselves. However, even while it is acting as a source of input knowledge in these three situations, the organisational memory is being further enriched by the knowledge crystallised in the solutions being developed.

The stock of knowledge on which KIBS providers draw for their main input is essentially the product of past experiences that have been memorised. Since they are the product of individual efforts, these experiences are embodied in individuals or groups of individuals. As a result, the organisational memory of KIBS firms is heavily dependent on the loyalty of its staff. The loss of certain members of staff produces an effect akin to amnesia or a cognitive haemorrhage. Stinchcombe and Heimer (1988), for example, described IT service providers as "precarious monopolies", constantly prey to the risk that their best experts will leave, taking with them the expertise that is also publicized by the companies, which further increases the risk of defections.

However, a part of each individual experience exists in codified form. Documents, reports (as hard copies or in electronic form), software, films, recordings, models, prototypes and technical systems are constantly circulating among the various actors engaged in the provision of a given service. This type of knowledge is more easily accumulated. It transforms individual experiences into a collective memory that can be drawn on at any time and in any place by all the members of the organisation. The largest KIBS firms, which are very conscious of the phenomena associated with knowledge localisation and their perverse effects, particularly the formation of cliques that may cause the organisation to fragment (Granovetter, 1973), routinely put in place codification or externalisation strategies. These strategies may take various forms: the accumulation of knowledge derived from experience in databases, the use of structuring methods etc.

However, it should not be concluded that the trade-off between externalisation-generalisation and internalisation-localisation is always resolved in favour of the first pair. In reality, there is a dialectical relationship between the two that can be interpreted by means of a paradoxical mechanism that Eisenberg (1984) calls "unified identity", that is some degree of balance between two apparently contradictory mechanisms, namely a diversity of interpretations and their simultaneous unicity (that is the construction of consensus).

From the KIBS provider's point of view, what really matters is the establishment of a cognitive differential between the organisation and its clients. In other words, it needs to expand its organisational memory. This is achieved through the combination of two knowledge-accumulation strategies:

- accumulation in individual memories, that is the training of individuals and the recruitment and outplacement of experts. Training may be formalised or take place on the job (internalisation and socialisation principles in Nonaka's sense of the terms). The recruitment of experts may expand the memory quantitatively or mechanically (recruitment of an additional expert in order to strengthen and existing speciality) as well as qualitatively (recruitment in a new area of expertise). Outplacement also reflects a qualitative change in the memory, particularly when "up or out" strategies are being implemented.

- the accumulation of knowledge on inanimate media, that is the codification of knowledge in libraries, databases, expert systems, methods, standard contracts, publications etc.

The first of these knowledge-accumulation strategies produces diversity and creative ambiguity. The second produces unity, or common knowledge. Once combined, they generate "unified diversity". 


\section{Knowledge processing and innovation in and through the use of KIBS}

The question of knowledge processing is closely linked to that of innovation, particularly in the evolutionary approach. Like innovation, KIBS are often defined as activities intended to resolve selected (and sometimes "reconstructed") problems. However, the notion that all KIBS transactions are to be regarded as innovations should be rejected. Thus one important problem that has to be resolved in any economic analysis of KIBS is that of the boundary between a routine or standard service and an innovative service.

The link between innovation and KIBS can be considered from two different, though not unrelated perspectives, namely that of innovation produced through the use of KIBS and that of innovation within KIBS themselves.

\subsection{Innovation through the use of KIBS}

We are dealing here with the role that KIBS can play in assisting client firms to innovate. Two different scenarios can be envisaged.

In the first, the KIBS is mobilised in order to provide the knowledge-processing competences required for an innovation project (whether technological, organisational or strategic in nature) that has been fully identified as such by the client.

In the second, the KIBS is called on to play a part in a "non-programmed" innovation that will be denoted by the term "ad hoc innovation". This scenario will be examined in greater detail in the following section, since it involves both innovation through the use of KIBS and innovation within KIBS themselves.

Whatever the scenario under consideration, this model of KIBS-assisted innovation can be broken down into four component parts (Gallouj, 1999):

1) The functions (F) of the client firm that are the object of the innovation. The innovation may concern one or more of the firm's functions (legal, IT, research etc.). A functional approach of this kind to the object of innovation has several advantages. It is consistent with certain KIBS typologies that define service providers in terms of the main function of the client firm on which they act in order to produce change (the legal function in the case of legal consultants, for example). It also facilitates the introduction of a broadly-based, open concept of innovation, which encompasses not only new products and processes but also new strategies and new forms of organisation. The adoption of a functional approach to the object of innovation makes it possible to analyse in much greater detail these last two categories (particularly organisational innovation), which very often serve as residual, catch-all categories. Moreover, this functional approach, located upstream of products and processes, can be used to explain innovation in manufacturing and services with a certain degree of consistency (whatever the possible differences in content between the corresponding product and process innovations).

2) The degree of interaction (C) between the service provider and client around the innovation project or emerging innovation. In the case of "non-programmed" innovation, the degree of interaction around the innovation becomes conjoined with the degree of interaction involved in the provision of the service. In the case of an innovation project identified as such from the outset, the interaction revolves entirely around the innovation. The client participates to a greater or lesser extent in the provision of the service. In many cases, a non-programmed innovation emerges out of an intense service relationship. When a service provider is taking part in a clearly identified innovation project, the degree of interaction is highly 
variable. In particular, it depends on the stage of the process at which the service provider is called in. Indeed, the service provider may be called on before the innovation project proper gets underway in order to supply simple codified information, such as that produced by market surveys, which does not require any real interaction.

3) The stages of the innovation process (I) at which the service provider is called in. This process can be conveniently represented in terms of the following traditional sequence: 1) the gathering of information and ideas, 2) research (whether basic or applied), 3) design and development (including testing or experimentation), 4) the production of the solution, 5) the marketing of the solution (or its pseudomarketing when it is to be diffused within an organisation).

From the client firm's point of view, this process of innovation is never a linear one. The sequence outlined above is merely an heuristic device: the various stages may not all take place, some may overlap (i.e. take place simultaneously) and others may merge with each other (in services, for example, production and marketing are frequently synonymous).

From the service provider's point of view, this process (I) may also be approached in various ways. He may be called on to intervene in one stage only or in several stages. He may also be called on to take responsibility for the overall coherence of the project. Finally, several different providers may be called on to provide their own particular specialist services (marketing consultants upstream of the innovation, R\&D laboratories, legal consultants downstream of the solution, etc.). The strategies adopted by the major international auditing and consultancy companies are designed to make available to their clients a whole range of services in an integrated way (Gadrey et al., 1992).

4) The various knowledge-processing competences $(T)$. These competences are those outlined in section 2 above, that is the basic logistical competences, together with those of externalisation, internalisation, generalisation, localisation, association and dissociation.

A service provider called in to assist a client engaged in innovation may mobilise one, some or all of these competences. As Figure 2 shows, the model of KIBS-assisted innovation may take a multiplicity of configurations equating to sets $\{\mathrm{I}, \mathrm{T}, \mathrm{F}, \mathrm{C}\}$. One particular configuration merits particular attention, namely the one that describes the mobilisation of basic logistical competences within the framework of an innovation project. This configuration, which might be described as the standard configuration, consists of the simple transfer from source to receiver of codified information, without any real interaction between processor and receiver and irrespective of the various components of the innovation process and of the functions being considered. 


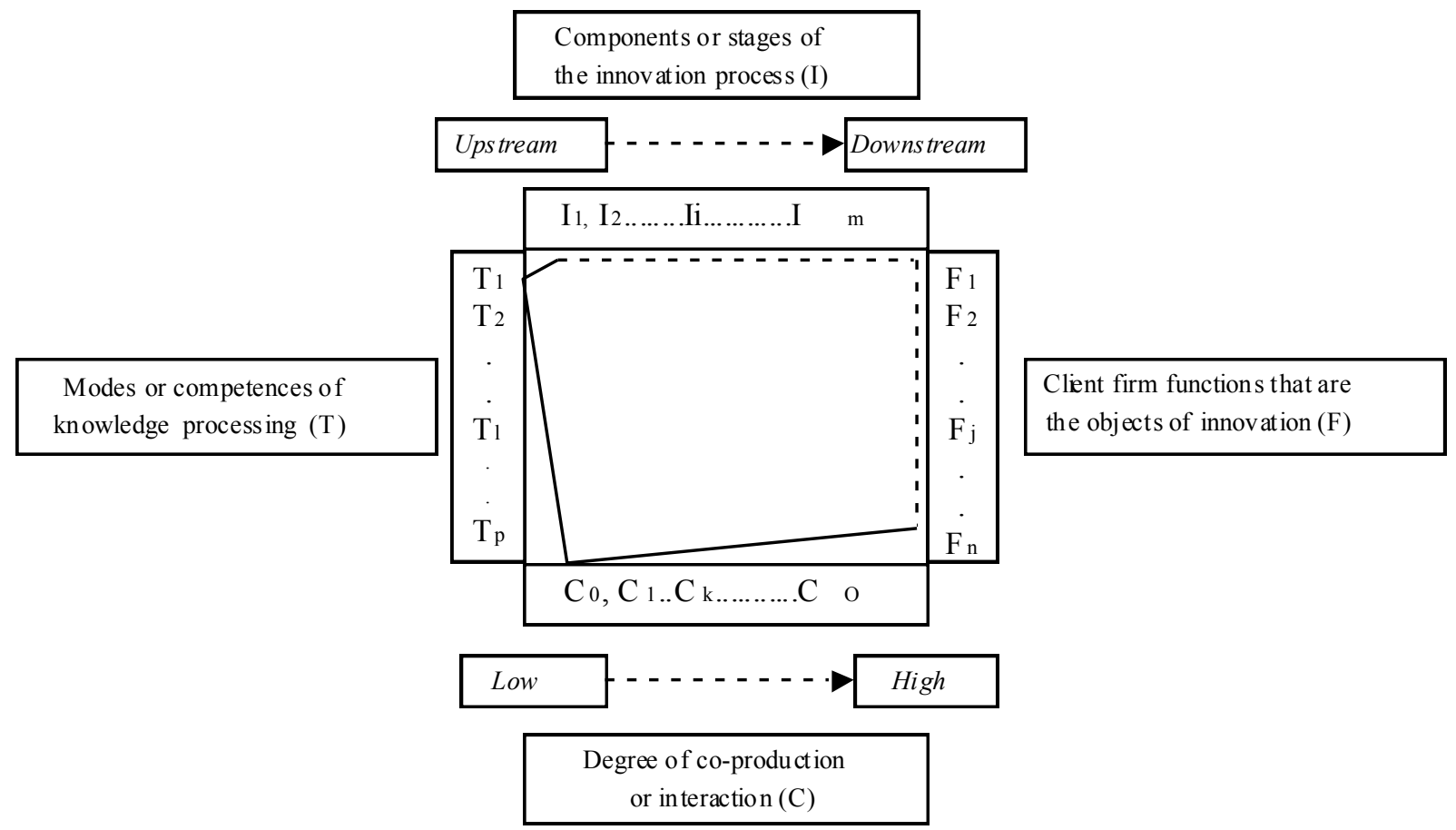

Figure 2 : the KIBS-assisted innovation model

The boundary between a KIBS provider's normal problem-resolving activities and his contribution to innovation is a fragile one. For example, legal services routinely provided by lawyers involve the processing of knowledge on behalf of clients. Such processing implies the implementation (in a multiplicity of configurations) of transfer, internalisation, externalisation, association, dissociation, generalisation and localisation competences. Even when he is producing a novel legal solution on behalf of a client (an innovation), a service provider is calling on the same knowledge-processing competences. In both cases, the competences mobilised are, to varying degrees, vectors of novelty, depending on whether they are exploitation competences (e.g. generalisation) or exploration competences (e.g. association).

Thus it is not the modes of knowledge processing (i.e. the competences) that define innovation by services (innovation does not occur solely when the Schumpeterian combinatory mechanism is brought into play), but rather the existence, a priori, of a clearly identified innovation project or the recognition, a posteriori, of an innovation and its designation as such (what might almost be called its social construction). In our model of KIBS-assisted innovation (cf. Figure 1), this innovation is represented by the $[\mathrm{I}]$ axis. This means that, when a service provider takes part in an innovation project with a client, the service provider is a (co)-producer of the innovation, even if the only competences mobilised are those that would ordinarily be mobilised when a normal service is provided. Thus there is no theoretical reason why the activities of external KIBS providers should be excluded from definitions of innovation indicators (as certain national and international statistical institutes do, for example, particularly the OECD).

\subsection{Innovation in KIBS}


Although KIBS providers assist their clients in the production of innovation, they may also innovate internally. In order to understand the nature of innovation in this type of activity, we must not allow ourselves to becoming entrapped in traditional categories. Rather we must seek to supplement and adapt them. Since KIBS providers process and produce knowledge, it seems to us appropriate to consider the innovation they produce in the same terms. Empirical studies (Gallouj, 1991) have revealed various types of innovations that can be inferred from a particular relationship to knowledge.

Innovation can be defined as the creation of new knowledge in order to resolve a problem. This new knowledge may be created intentionally, as is the case with "new fields of knowledge innovation" and "formalisation innovation". However, it may also emerge unintentionally out of various activities, as is the case with ad hoc innovation.

1) Ad hoc innovation is a solution (that is a set of knowledge) that allows a certain degree of new light (we are dealing here with an incremental innovation) to be shed on a firm's (legal, organisational, strategic, technical etc.) problem, without it necessarily being possible to transfer the solution in toto to other firms. Ad hoc innovation requires the service provider to have detailed knowledge of the client firm's problem, knowledge which is usually generated through an extremely interactive relationship. Thus ad hoc innovation is co-produced. It is also an innovation produced within KIBS and through the use of KIBS. It depends heavily on the competences of socialisation, internalisation and localisation. As a result, it poses problems of appropriation and pricing. However, once this ad hoc innovation has been produced, the externalisation and generalisation competences are deployed in order to incorporate it into the service provider's organisational memory so that certain elements of it can be reproduced elsewhere. In this way, ad hoc innovation (output knowledge) is transformed into input knowledge.

2) New fields of knowledge innovation. By analogy with Schumpeter's categories, and in view of the fact that, for KIBS providers, knowledge is both input and output, we can say that "new fields of knowledge" innovation encompasses 1) new products, 2) new markets and 3) new sources of raw materials. "New fields of knowledge" innovation denotes the accumulation of input knowledge relating to emerging spheres of knowledge (the Internet is perhaps the best current example) with a view to providing services (output knowledge) in these new spheres. The degree of novelty here is greater than in ad hoc innovation.

The principal (internal) competences deployed in this process of knowledge accumulation are characterised by their diversity: reciprocation (analogy, metaphors), combination and externalisation. However, since the new sphere of knowledge is initially a quasi-public good, with the economic properties characteristic of this type of good, certain specification and consolidation activities are required in order to establish a dominant design that can then be appropriated.

3) Formalisation innovation. This term denotes a heterogeneous group that includes all the mechanisms that serve to give form to the service in question (process, methods, organisation etc.). It relies heavily, therefore, on all the knowledge-processing competences that give solutions a certain degree of "visibility" and "stability" (externalisation, generalisation etc.).

\section{Conclusion}

If firms are processors of knowledge, as some recent studies suggest (Fransman, 1994), then KIBS firms are the best possible exemplification of the thesis, since knowledge, in all its forms, is both their main input and their main output.

We have been concerned in this paper with the activities of KIBS providers, the main objective of which is to make knowledge-processing capacities available to clients. These capacities can be described satisfactorily in terms of a certain number of basic mechanisms (which we have denoted by the term 
competence) that modify the spatial characteristics, form, scope or architecture of the knowledge in question.

These are the same basic mechanisms (competences) that are mobilised in innovation projects (whether ad hoc or identified as such). Nevertheless, it should not be thought that all KIBS transactions constitute innovations, and although the knowledge-processing competences may be either exploitation or exploration competences (March, 1981), what distinguishes a routine service from an innovative service is the existence of an innovation project or its "social construction" or designation as such in the course of service delivery.

As far as innovation in KIBS is concerned, it cannot be said to be independent of innovation through the use of KIBS. Indeed, both forms of innovation draw on the same organisational memory and feed back into the same memory. Moreover, the highly interactive nature of many knowledge-intensive business services confuses the ownership regimes of certain forms of innovation.

There is some value in considering the nature of innovation in KIBS in cognitive terms by virtue of the cognitive nature of the input and, particularly, the output of such services. The various forms of innovation thus revealed are also related in specific ways to the various basic knowledge-processing mechanisms.

\section{Bibliography}

Abernathy, W., Utterback, J. 1978. Patterns of Industrial Innovation, Technology Review, 80, juin-juillet, p. 41-47.

Antonelli, C. 1999. The evolution of the industrial organisation of the production of knowledge, Cambridge Journal of Economics, 23, p. 243-260.

Antonelli, C. 1996. Localized knowledge percolation processes and information networks, Journal of Evolutionary Economics, 6, p. 281-295.

Arrow, K. 1962. Economic Welfare and the allocation of resources for invention, in Nelson, R.R. (ed). The rate and direction of inventive activity : economic and social factors, Princeton University Press.

Bessant, J., Rush, H. 1995. Building bridges for innovation: the role of consultants in technology transfer, Research Policy, 24, p. 97-114.

Bilderbeek, R., Den Hertog, P. 1997. The new knowledge infrastructure: the role of technologies based knowledge-intensive business services in national innovation systems, SI4S project, European Commission (DG XII), TSER program.

Callon, M. 1986. Eléments pour une sociologie de la traduction. La domestication des coquilles SaintJacques et des marins-pêcheurs dans la baie de Saint-Brieuc, L'année sociologique, n³6 p. 169-208.

Callon, M. 1999. Le réseau comme forme émergente et comme modalité de coordination : le cas des interactions stratégiques entre firmes industrielles et laboratoires académiques, in Callon et al. Réseau et coordination, Economica.

Cohen, M., Levinthal, D. 1990. Absorptive capacity: a new perspective on learning and innovation, Administrative Science Quarterly, 35, p. 128-152.

Cohen, M.D., Bacdayan, P. 1996. Organizational routines are stored as procedural memory : evidence from a laboratory study, in Meindl et al. (eds).

Cohendet, P., Kern, F., Mehmanpazir, B., Munier, F. 1999. Knowledge coordination, competence creation and integrated networks in globalised firms, Cambridge Journal of Economics, 23, p. 225-241.

Cowan, R., Foray, D. 1998. Economie de la codification et de la diffusion des connaissances, in Petit (ed).

Dasgupta, P., David, P.A. 1994. Towards a new economics of science, Research Policy, 23, p. 487-521.

De Bandt, J., Gadrey, J. (Eds) 1994. Relations de service, marchés des services, CNRS Editions. 
Eisenberg, E.M. 1984. Ambiguity as strategy in organizational communication, Communication monographs, 51, p. 227-242.

Foray, D., Mairesse, J. 1999. Economie de la connaissance, miméo.

Fransman, M. 1994. Information, knowledge, vision and theories of the firm, Industrial and Corporate Change, Vol. 3, n³, p. 713-757.

Gadrey, J. 1996. Services : la productivité en question, Desclée de Brouwer.

Gadrey, J. 2000. La caractérisation des biens et des services d'Adam Smith à Peter Hill : une approche alternative, Colloque "Services in the international perspective ", Lille, juin.

Gadrey, J. et al. 1992. Manager le Conseil, Ediscience.

Gallouj, C., Gallouj, F. 1996. L'innovation dans les services, Editions Economica Poche, Paris.

Gallouj, F. 1991. Les formes de l'innovation dans les services de conseil, Revue d'économie industrielle, n'57, p. 25-45.

Gallouj, F. 1999. L'innovation interactionnelle : un modèle néoschumpeterien, Colloque économie de la proximité, Toulouse, mai.

Gallouj, F., Weinstein, O. 1997. Innovation in services, Research Policy, 26, p. 537-556.

Gibbons, M., Johnston, R. 1974. The role of science in technological innovation, Research Policy, 3, p. 220-242.

Granovetter, M. 1973. The strength of weak ties, American Journal of Sociology, Vol. 78, nº, p. 13601380 .

Hales, M. 1997. Make or buy in the production of innovation: competences, fullness of services and the architecture of supply in consultancy, SI4S project, European Commission (DG XII), TSER program.

Hayek, F. 1945. The use of knowledge in society, American Economic Review, 35, n²4, p. 519-530.

Johnson, B. 1992. Institutional learning, in Lundvall, B.A. (ed). National systems of innovation, Pinter Publishers.

Kirzner, I. 1979. Perception, Opportunity and Profit. Studies in the Theory of Entrepreneurship, University of Chicago Press.

Kubr, M. 1988. Management Consulting : a Guide to the Profession, BIT, Genève.

Lippman, S., Rumelt, R.P. 1982. Uncertain imitability : an analysis of interfirm differences in efficiency under competition, Bell Journal of Economics, Vol. 13, p. 418-438.

Lundvall, B.A, Johnson ,B. 1994. The learning Economy, Journal of Industry Studies, Vol. 1, n², décembre, p. 23-42.

Machlup, F. 1984. Knowledge: its creation, distribution and economic significance, Vol. III. The Economics of Information and human capital, Princeton University Press.

March, J.G. 1991. Exploration and exploitation in organizational learning, Organization Science, Vol. 2, p. 71-87.

Maskell, P. Malmberg, A. 1999. Localised learning and industrial competitiveness, Cambridge Journal of Economics, 23, p. 167-185.

Meindl ,J.R., Stubbart, C., Porac, J.F. (eds) 1996. Cognition within and between organizations, Sage publications.

Miles, I., Kastrinos, N., Flanagan, K., Bilderbek, R., den Hertog, P., Huntink, W., Bouman, M. 1994. Knowledge-Intensive Business Services: Their Role as Users, Carriers and Sources of Innovation, PREST, University of Manchester.

Nelson, R. 1994. The co-evolution of technology, industrial structure and supporting institutions, Industrial and Corporate Change, Vol. 3.

Nonaka, S. 1994. A dynamic theory of organizational knowledge creation, Organization Science, Vol. 5, $\mathrm{n}^{\circ} 1, \mathrm{p} .14-37$.

Nonaka, S., Takeuchi, N. 1995.The knowledge-creating company, Oxford University Press.

Noteboom, B. 1992. Towards a dynamic theory of transactions, Journal of evolutionary economics, 2, p. 281-299.

Noteboom, B. 1999. Innovation, learning and industrial organisation, Cambridge Journal of Economics, 23, p. $127-150$. 
Peirce, C.S. 1957. Essays in the philosophy of science, Bobbs-Merrill.

Petit, P. (ed) 1998. L'économie de l'information, La Découverte.

Piaget, J. 1970. Psychologie et épistémologie, Paris, Denoël.

Polanyi, M. 1983. The tacit dimension, Peter Smith ( 1 ère édition 1966).

Ribault, T. 1991. Formes et limites de la marchandisation de l'information, Thèse de Doctorat, Université de Lille I.

Rubalcaba-Bermejo, L. 1999. Business Services in European Industry, European Commission, DG IIIIndustry.

Senker, J. 1995. Knowledge and models of innovation, Industrial and Corporate Change, Vol. 4, n², $\mathrm{p}$. 425-447.

Starbuck, W.H. 1996. Learning by knowledge-intensive firms, in Cohen M.D. Sproull, L.S. (Eds), Organizational Learning, Sage Publications.

Stinchcombe, A., Heimer, C. 1988. Interorganizational relations and careers in computer software firms, Research in the Sociolgy of work, vol. 4., p. 179-204.

Sundbo, J. 1998. The organisation of innovation in services, Roskilde University Press.

Teece, D.J. 1988. Technological change and the nature of the firm, in Dosi et al. (eds) Technical Change and Economic Theory, Pinter Publishers.

Thévenot, L. 1988. Les investissements de forme, Cahiers du Centre de l'étude et de l'emploi, p. 21-73.

Winter, S. 1987. Knowledge and competence as strategic assets, in Teece, D.J. (Ed) The competitive challenge, Harper \& Row.

Wolff, E.N., Baumol, W.J. 1987. Sources of postwar growth of information activity in the U.S., Unpublished manuscript.

Zander, U., Kogut, B. 1995. Knowledge and the speed of the transfer and imitation of organisational capabilities. An empirical test, Organizational science, vol. 6, n¹, p. 76-92. 